\title{
Effect of Cryogenic Treatment on Micro-structure and Property of 45\# Steel
}

\author{
Hong Jun $\mathrm{Ni}^{1, \mathrm{a}}{ }^{*}, \mathrm{Yi} \mathrm{Lv}^{1, \mathrm{~b}}$, Le Mi ${ }^{1, \mathrm{c}}$, Hongmei Liu ${ }^{1,2, \mathrm{~d}}$ \\ ${ }^{1}$ School of Mechanical Engineering, Nantong University, Nantong, Jiangsu China, 226019 \\ ${ }^{2}$ Office of Nantong Wall Material Innovation, Nantong, Jiangsu, 226001, China )
}

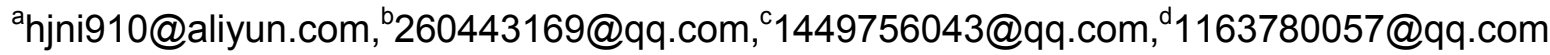

\begin{abstract}
Keyword:Cryo-treatment; 45 steel; Morphological Structure
Abstract: Attempts are made to treat 45 steel cryogenically using liquid nitrogen. Various properties of un-treated and cryo-treated 45 steel are studied in a comparative manner. The morphological changes are investigated by metallurgical microscope. Hardness is evaluated by the relevant machine. The results reveal that the micro-structure of 45 steel become compact and homogeneous during the cryogenic treatment, and the interlamellar spacing of pearlite become smaller. The cryogenic treatment is found to be an effective technique for enhancing hardness and wear performance.
\end{abstract}

\section{Introduction}

$45 \#$ steel is widely used in machinery manufacturing. The mechanical properties of steel is very good. It is It often used for shaft parts, blank material, and mold welding materials. In the actual production use, 45 steel inevitably happen to wear, and even rupture. So, demand 45 steel have higher wear resistance and hardness.

Cryogenic treatment ${ }^{[1-2]}$ as abnormal heat treatment, which refers to the liquid nitrogen for cooling medium in the environment of the lower than $100^{\circ} \mathrm{C}$ processing work piece, it can greatly improve the material mechanics performance. Its main reason is that cryogenic treatment can make the pear lite lamella smaller and make the internal organization to become more close. Material volume is contracted. Grain size is reduced. It causes micro-distortion or a large n-umber of dislocation, and makes material organization to become more uniform. At the same time, with the temperature reduce, on the surface material is the separation of ultrafine carbon atoms, and it has the effect of dispersion strengthening on the whole organization.

At present, a key method to improve the performance of 45 steel is hardening and tempering + surface quenching, carburizing on 45 steel surface treatment, as well as using severe plastic deformation to prepare ultra-fine grained metal. Document suggests that many scholars use cryogenic treatment to improve the service life of some special steel and polymer materials ${ }^{[3-5]}$. But the cryogenic study of 45 steel has not yet been reported. This article based on 45 steel cryogenic treatment is to improve its organization, and to improve its mechanical properties, ultimately to extend the service life of 45 steel.

\section{Experimental materials and methods}

All the sample piece from a production of 45 steel, the chemical components are shown in table 1 . 
Tab. 1 chemical composition of 45 steel

\begin{tabular}{|c|c|c|c|c|c|c|}
\hline \multicolumn{7}{|c|}{ quality score $\%$} \\
\hline$\omega \mathrm{C}$ & $\omega \mathrm{Si}$ & $\omega \mathrm{Mn}$ & $\omega \mathrm{Cr}$ & $\omega \mathrm{Ni}$ & $\omega \mathrm{Cu}$ & $\mathrm{Fe}$ \\
\hline 0.45 & 0.24 & 0.6 & $\leq 0.25$ & $\leq 0.3$ & $\leq 0.25$ & $\mathrm{Bal}$ \\
\hline
\end{tabular}

Experiment with 45 steel size is $20 \mathrm{~mm} \times \varphi 8 \mathrm{~mm}$, the sample is divided into two groups:1) Being in $850^{\circ} \mathrm{C}$ water quenching of 45 steel, and then to $600^{\circ} \mathrm{C}$ high temperature tempering, constant temperature 2 hours. 2) Being in $850^{\circ} \mathrm{C}$ water quenching of 45 steel, and then to $-180^{\circ} \mathrm{C}$ cryogenic treatment, constant temperature 23 hours. Using the Rockwell hardness tester (HR-150A) to measure the hardness of 45 steel. Metallographic specimen is corroded by $4 \%$ nitric acid alcohol solution, and then observing each wire tissue morphology by metallographic electron microscope.

\section{Experimental results and analysis}

\section{Micro-structure observation}

The micro-structure of 45 steel is Fig. 2. It is 45 steel micro-structure after processing technique of the two groups. What is more,Fig. a is $850^{\circ} \mathrm{C}$ quenching $+600^{\circ} \mathrm{C}$ high temperature tempering $\times 2 \mathrm{~h}$. And Fig. $\mathrm{b}$ is $850^{\circ} \mathrm{C}$ quenching $+-180^{\circ} \mathrm{C}$ cryogenic $\times 23 \mathrm{~h}$.

From the Fig. 2 (a), it is observed that this is typical of pearlite. Pearlite group show equiaxed shape and the adjacent pearlite lamella has no obvious preferred orientation. And From Fig. 2 (b), it is observed that after cryogenic treatment of samples in the organization clearly have a lot of acicular Martensite. That is because there are still much Austenite in the sample, transformed into Martensite with the help of deep cold temperature. And sample organization becomes more homogeneous,

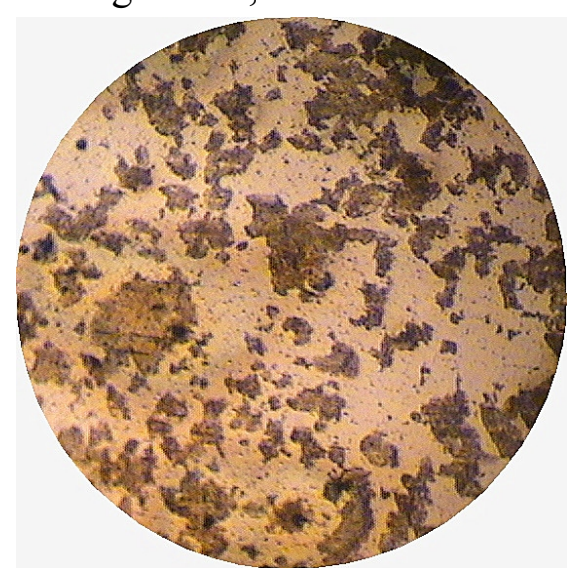

(a) $200 \mathrm{~T}$

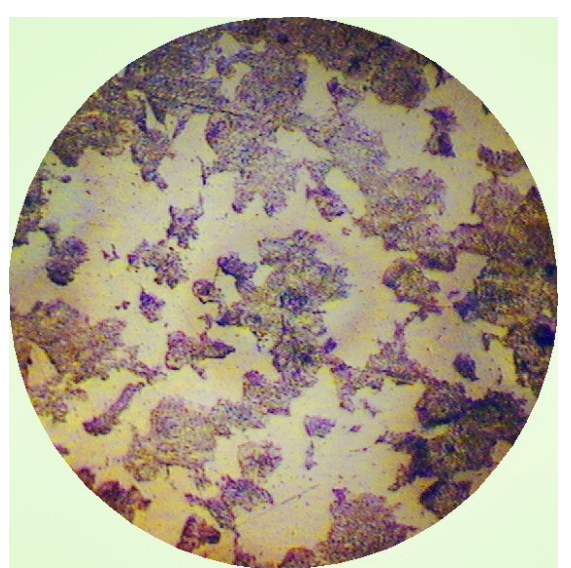

$400 \mathrm{~T}$ 


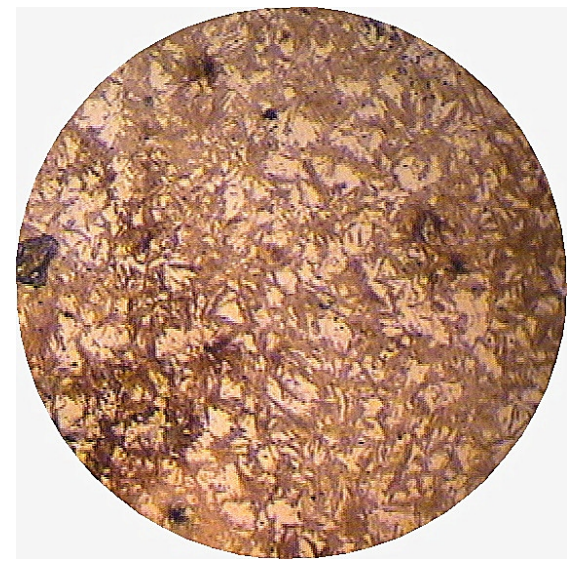

(b) $200 \mathrm{~T}$

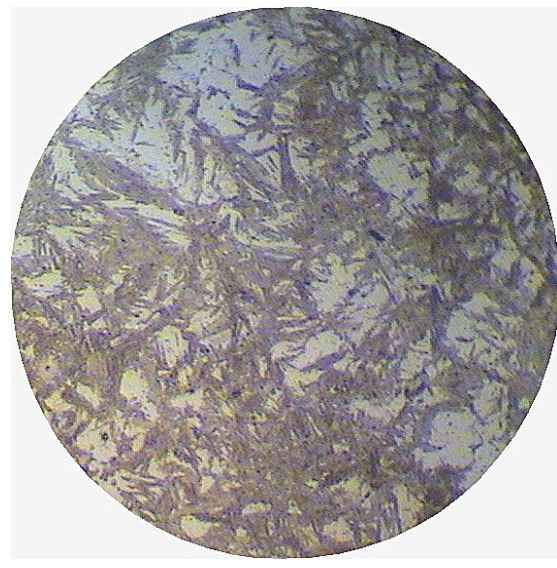

$400 \mathrm{~T}$

Fig.2 SEM of cross and vertical surface of 45 steel with different cryogenic treatment suggesting that organization of 45 steel has been further elaboration. Carefully study the organize of the samples, superfine carbide is found on the surface of treated cryogenically samples.

This may be due to the micro-structure in the process of cryogenic shrinkage ${ }^{[6]}$, and thermal expansion coefficient of ferrite was obviously higher than that of carbon atoms. What is more, some cracks within the grain, make the grain size decrease.The retained austenite ${ }^{[7]}$ present after conventional heat treatment process can be alleviated by means of cryo-treated by transferring into martensite as austenite is soft and unstable at lower temperatures. Because in most of the steels the martensite temperature does not lie above room temperature,the steel has to be cooled still further, to achieve $100 \%$ martensite. cryogenic is an extension of conventional heat treatment process by which it is possible to achieve $100 \%$ martensite transformation This treatment alters metallurgical properties and improves the strength of the steel.

\section{Mechanics Performance Testing}

The hardness of selected cryo-treated and un-treated 45 steel samples are tested by the relevant machine, the average hardness data and treatment process are shown below in Table 2 . The average hardness of un-treated sample is $51.08 \mathrm{HRC}$. Whereas, The sample treated for $23 \mathrm{~h}$ at $-180^{\circ} \mathrm{C}$ show an enhancement by $4 \%$ than un-treated sample. This can be correlated with the crystallite size of the sample, as the crystallite

Tab. 2 hardness of 45 steel with different treatment

\begin{tabular}{ccccccc}
\hline Hardness & 1 & 2 & 3 & 4 & 5 & Average \\
\hline $\begin{array}{c}850^{\circ} \mathrm{C} \\
\text { Process } \\
\text { temper } \times 2 \mathrm{~h} \times 0^{\circ} \mathrm{C} \\
\quad 850^{\circ} \mathrm{C}\end{array}$ & 50.7 & 50.5 & 51.2 & 51.8 & 51.2 & 51.08 \\
$\begin{array}{c}\text { quench }+-180^{\circ} \mathrm{C} \\
\times 23 \mathrm{~h}\end{array}$ & 53.9 & 52.8 & 52.0 & 53.3 & 53.2 & 53.04 \\
\hline
\end{tabular}

size decreases and the material micro-structure becomes homogeneous, hardness increases as mentioned by Callister ${ }^{[8]}$. In addition, saturability of carbon atom increases because of cryogenic treatment, there is more carbon atom on the surface of 45 Steel, as a result of the enhancement of 
hardness and wear performance. At last, As a result of retained Austenite turned into Martensite, the increase in hardness due to the Martensite with better property, with the help of Lhymn's equation, which indicates that hardness is directly proportional to abrasive wear performance.

\section{Conclusion}

(1) In order to improve the mechanical properties of $45 \mathrm{Steel}$, they needs to be treated cryogenically under controlled temperature.

(2) During this investigation, the cryogenic treatment is found to be an effective technique for enhancing the hardness and abrasive wear performance of the studied 45 Steel. Increase in \% crystallinity was found to be the most important parameter responsible for the hardness and wear performance enhancement.

(3) The enhancement in hardness property and wear performance enhancement of PA can be attributed to increase in carbon atom, modification in micro-structure, conversion of less stable phases into more stable phases and formation of complex phases.

\section{Acknowledgments}

This work is supported by Application Research Project of Jiangsu Committee([2013]742-1) and the Natural Science Research Project of Nantong University of Jiangsu.

Corresponding author: Tel: +86 13338061306; Email address: hjni910@aliyun.com (Hongjun Ni )

\section{References}

[1] He. H, Yue Q. Journal of Hazardous Materials.Vol.203(2011),p.53-61.

[2] Zhang Liaoyuan, Wang Shuo. Applied Mechanics and Materials. Vol. 395(201 3) ,p.1044-1048.

[3] P. Baldissera, C. Delprete.The Open Mechanical Engineering Journal, 2008,(2): $1-11$.

[4] Tao Qian, Michael Marx, Kerstin Schüler, et al. Acta Mater,2010,58(6):2112

[5] Shen Feng, Zhou Jianqiu, Liu Yingguang, et al. Comput Mater Sci,2010,49(2):226

[6] K. N. Pande, D. R. Peshwe, Anupama Kumar.Trans Indian Inst Met. 2012, 65(3): $313-319$.

[7] Sreerama Reddy,T.V.; Sornakumar, T.; Reddy,M.V.; Venkatram,R.; Senthilkumar, Machining Science and Technology.2009, 13 (2), 269-281.

[8] Yong, A.Y.; Seah, K.H.W.; Rahman, M.. International Journal of Machine Tools\&Manufacture.2006, 46, 2051-2056. 